\title{
Patient knowledge on reporting adverse drug reactions in Poland
}

\author{
This article was published in the following Dove Press journal: \\ Patient Preference and Adherence \\ 29 December 2016 \\ Number of times this article has been viewed
}

\author{
Anna Staniszewska' \\ Marta Dąbrowska-Bender ${ }^{2}$ \\ Dominik Olejniczak² \\ Aneta Duda-Zalewska ${ }^{2}$ \\ Magdalena Bujalska- \\ Zadrożny ${ }^{3}$ \\ 'Department of Experimental and \\ Clinical Pharmacology, ${ }^{2}$ Department \\ of Public Health, ${ }^{3}$ Department of \\ Pharmacodynamics, Medical University \\ of Warsaw, Warsaw, Poland
}

Correspondence: Anna Staniszewska Department of Experimental and Clinical Pharmacology, Medical University in Warsaw, Banacha Ib Street, 02-067 Warsaw, Poland

Tel/fax +4822II6 61 60

Email anna.staniszewska@wum.edu.pl
Aim: The aim of the study was to assess patient knowledge on reporting of adverse drug reactions.

Materials and methods: A prospective study was conducted among 200 patients. The study was based on an original survey composed of 15 single- and multiple-choice questions. The study involved individuals who have experienced adverse reactions as well as individuals who have never experienced any adverse reactions; people over the age of 18; literate; residing in Mazowieckie Voivodeship, who have not been diagnosed with any disease that could compromise their logical thinking skills.

Results: The respondents who lived in the city had a greater knowledge compared to the respondents who lived in the countryside (Pearson's $\chi^{2}=47.70, P=0.0013$ ). The respondents who lived in the city were also more statistically likely to provide a correct answer to the question about the type of adverse reactions to be reported (Pearson's $\chi^{2}=50.66, P=0.012$ ). Statistically significant associations were found between the place of residence of the respondents and the correct answer to the question about the data that must be included in the report on adverse reactions (Pearson's $\chi^{2}=11.7, P<0.0001$ ).

Keywords: adverse reactions, medicinal products, pharmacovigilance, Mazowieckie Voivodeship

\section{Introduction}

Every medicinal product administered to living organisms should be effective and safe. For this reason, before it is introduced on the market, it has to undergo clinical research. Unfortunately, there are many limitations on research and not all side effects are identified in the course of it. The limitations comprise, among others, a relatively short time of exposure of a patient to a drug, a relatively small number of participants (around 1,500), multiple exclusion criteria, or the fact that clinical research is conducted under conditions that are different from the conditions of everyday practice. ${ }^{1,2}$ For this reason, the monitoring of a drug is not finished at the moment of introduction on the market. The process of collecting and analyzing data on safety of drugs after registration is referred to as pharmacovigilance. ${ }^{3}$

The global program for collecting information on adverse drug reactions (ADRs) (Program for International Drug Monitoring) of WHO was launched in 1968 in Uppsala, Sweden. ${ }^{4}$ Poland joined the program in $1972 .{ }^{5}$ The aim of the program is to identify unknown risks associated with the use of a given drug. ${ }^{4}$

In Poland, all suspected adverse reactions of medicinal products intended for human use are supposed to be reported to the Department for Monitoring Adverse Reactions of Medicinal Products at the Office for Registration of Medicinal Products, Medical 
Devices and Biocidal Products. Adverse reactions might also be reported to the accountable entity that will then inform the above authority. ${ }^{6}$

According to applicable regulations, in Poland (Polish law - at. 12a in The Pharmaceutical Law, 6 September 2001r. (Dz. U. z 2008r. Nr 45, poz. 271, z późn. zm.) implement European Law - Directive 2010/84/EU of the European Parliament and of the Council of 15 December 2010 amending, as regards pharmacovigilance, Directive 2001/83/EC on the Community code relating to medicinal products for human use medical personnel (eg, doctors, pharmacists) are obliged to report adverse drug reactions (ADRs) and patients too, can report adverse reactions of drugs. ${ }^{7}$

ADRs might be reported by means of the so-called yellow card developed by the Office for Registration of Medicinal Products, Medical Devices, and Biocidal Products (URPLW$\mathrm{MiPB}$ ) or the international form developed by the Council for International Organizations of Medical Sciences (CIOMS). Furthermore, some accountable entities have their own forms and if there are no ready-made forms to use, the adverse reactions might be reported on a normal sheet of paper that will contain the minimum required data. ${ }^{8}$

\section{Aim of the study}

The aim of the study was to assess patient knowledge on reporting of ADRs. Specific objectives were to check whether the patients know how to proceed in an event of occurrence of any adverse reactions and how they should be reported.

\section{Materials and methods}

A prospective study was conducted in January-May 2016 among patients of a Warsaw-based multispecialist clinic. The study was based on an original survey composed of 15 single- and multiple-choice questions. The questionnaire was divided into two sections; demographic characteristics and ADRs reporting knowledge. Demographic characteristics consisted of six items; age, sex, educational level, place of living, medications, and side-effect history. In the second part, the respondents answered questions concerning the means of reporting of ADRs (6 questions) and the data that must be included in the report on ADRs (3 questions). Tables 1-3 show all the possible answers. The questionnaire was subjected to validity by sending to pharmacy academics who work in Department for Monitoring Adverse Reactions of Medicinal Products at the Office for Registration of Medicinal Products, Medical Devices and Biocidal Products in Warsaw. Their feedbacks were incorporated. The instrument was then administered to 5 males and 5 females. The respondents were advised of the purpose of the study.
Table I Characteristics of patients participating in the survey

\begin{tabular}{ll}
\hline Characteristics & $\mathbf{N}(\%)$ \\
\hline Total & $200(100)$ \\
Gender & $176(88)$ \\
Female & $24(12)$ \\
Male & \\
Age, years & $28.43(8.68)$ \\
Mean (SD) & $20-70$ \\
Range & \\
Education & $4(2)$ \\
Primary & $10(5)$ \\
Vocational & $140(70)$ \\
Secondary & $46(23)$ \\
University & \\
Place of living & $124(62)$ \\
Urban area & $76(38)$ \\
Rural area & \\
Taking drugs & $180(90)$ \\
Ad hoc & $20(10)$ \\
Chronically & \\
Adverse drug reaction & $16(8)$ \\
Yes & $184(92)$ \\
No &
\end{tabular}

Abbreviation: SD, standard deviation.

The participation was voluntary and anonymous. The study involved individuals who have experienced adverse reactions as well as individuals who have never experienced any adverse reactions; people over the age of 18; literate; residing in Mazowieckie Voivodeship, who have not been diagnosed with any disease that could compromise their logical thinking skills. Initially, 228 patients agreed to participate in the study. The final analysis covered surveys completed by 200 patients. The remaining 28 surveys were rejected due to missing information. The data was analyzed by descriptive statistics and nonparametric $\chi^{2}$ test (ie, comparisons of percentage of responses by sex, age, and place of residence).

Ethical Committee consent for the presented research was not required. According to the statement of the Ethical Committee of the Medical University of Warsaw: "The Committee does not provide opinions on surveys, retrospective studies, or other non-invasive research" (Detailed information and templates of documents of Ethics Committee of Medical University of Warsaw (Accessed 201610-01): http://komisjabioetyczna.wum.edu.pl/content/ szczeg $\%$ C3\%B3\%C5\%82owe-informacje-orazwzorydokument $\% \mathrm{C} 3 \% \mathrm{~B} 3 \mathrm{w}$. Completion of the survey meant that the patients gave their consent to participate in this study.

\section{Results \\ Description of the sample group}

Eighty-eight percent (176 individuals) of the 200 who qualified for the study were women and $12 \%$ (24 individuals) were men. 
Table 2 The answers given by the respondents to the question about the means of reporting of adverse drug reactions

\begin{tabular}{|c|c|c|}
\hline Variables & Answers & Percentage \\
\hline Individuals & Doctor & $90 \%$ \\
\hline entitled & Patient & $75 \%$ \\
\hline to report & Pharmacist & $45 \%$ \\
\hline adverse drug & Pharmacy technician & $31 \%$ \\
\hline \multirow[t]{5}{*}{ reactions } & Dietician & $26 \%$ \\
\hline & Nurse/midwife & $22 \%$ \\
\hline & Paramedic & $19 \%$ \\
\hline & Dentist & $11 \%$ \\
\hline & Veterinarian & $5 \%$ \\
\hline \multirow{13}{*}{$\begin{array}{l}\text { Place of } \\
\text { reporting } \\
\text { adverse drug } \\
\text { reactions }\end{array}$} & Ministry of Health & $95 \%$ \\
\hline & URPLWMiPB & $90 \%$ \\
\hline & Main/Voivodeship Pharmaceutical & $65 \%$ \\
\hline & Inspectorate & \\
\hline & Chambers of Physicians/Pharmacists & $40 \%$ \\
\hline & Pharmaceutical company & $35 \%$ \\
\hline & National Health Fund & $32 \%$ \\
\hline & Agency for Health Technology Assessment & $22 \%$ \\
\hline & Clinic & $19 \%$ \\
\hline & Medical universities & $17 \%$ \\
\hline & Teaching hospitals & $15 \%$ \\
\hline & Main/Voivodeship Sanitary Inspectorate & $14 \%$ \\
\hline & Hospital/general pharmacy & $12 \%$ \\
\hline \multirow{5}{*}{$\begin{array}{l}\text { Adverse } \\
\text { drug reaction } \\
\text { reporting } \\
\text { tools }\end{array}$} & CIOMS form & $32 \%$ \\
\hline & $\begin{array}{l}\text { A form available on the website of the } \\
\text { pharmaceutical company }\end{array}$ & $27 \%$ \\
\hline & A sheet of paper with all required & $26 \%$ \\
\hline & information & \\
\hline & Yellow card & $8 \%$ \\
\hline \multirow{10}{*}{$\begin{array}{l}\text { Adverse } \\
\text { drug reaction } \\
\text { reporting } \\
\text { methods } \\
\text { Adverse drug } \\
\text { reactions } \\
\text { subject for } \\
\text { reporting }\end{array}$} & Only in person & $99 \%$ \\
\hline & Only by email & $72 \%$ \\
\hline & Only by post & $69 \%$ \\
\hline & In person, by email, by post & $69 \%$ \\
\hline & Serious adverse reactions & $67 \%$ \\
\hline & Reactions not covered by the package leaflet & $62 \%$ \\
\hline & Reactions covered by the package leaflet & $31 \%$ \\
\hline & Reactions that occur for the first time & $19 \%$ \\
\hline & in a given patient & \\
\hline & $\begin{array}{l}\text { Reactions that frequently occur in } \\
\text { a given patient }\end{array}$ & $11 \%$ \\
\hline \multirow{7}{*}{$\begin{array}{l}\text { Products not } \\
\text { covered by } \\
\text { the reporting } \\
\text { of adverse } \\
\text { reactions }\end{array}$} & Dietary supplements & $58 \%$ \\
\hline & Herbal medicines & $45 \%$ \\
\hline & Foodstuffs for particular nutritional use & $39 \%$ \\
\hline & Medical devices & $32 \%$ \\
\hline & Homeopathic medicines & $28 \%$ \\
\hline & Drugs applied in inpatient treatment & $22 \%$ \\
\hline & Imported drugs & $17 \%$ \\
\hline
\end{tabular}

Abbreviations: CIOMS, Council for International Organizations of Medical Sciences; URPLWMiPB, Registration of Medicinal Products, Medical Devices, and Biocidal Products.

The respondents were aged 20-70, with a mean age of $28.43 \pm 8.68$ years. The respondents were classified into three age groups. People aged 20-30, who accounted for $75 \%$ of the analyzed population, prevailed. People aged $30-50$ made up $20 \%$ of the general number, and people aged $50-70$ accounted for $5 \%$ of the respondents.

The majority of the analyzed population were people with secondary education (70\%); $23 \%$ of the individuals had
Table 3 The answers given by the respondents to the question about data that must be included in the report on adverse drug reactions

\begin{tabular}{lll}
\hline Variables & Answers & Percentage \\
\hline Information & First name and surname & $90 \%$ \\
on the & PESEL (personal identification number) & $72 \%$ \\
patient & Telephone number & $69 \%$ \\
& Address of residence & $61 \%$ \\
& Date of birth & $61 \%$ \\
& Sex & $52 \%$ \\
& NFZ branch identifier & $28 \%$ \\
& Weight & $19 \%$ \\
& NIP (tax identification number) & $12 \%$ \\
Information & Height & $9 \%$ \\
on the & Description of adverse reaction & $93 \%$ \\
drug and & Date of occurrence of adverse reaction & $88 \%$ \\
adverse & International name & $83 \%$ \\
reaction & Date of first and last administration of the drug & $78 \%$ \\
& Reason for application of the drug & $78 \%$ \\
& Drug dosage & $78 \%$ \\
& Description of adverse reaction & $72 \%$ \\
& Route of administration & $49 \%$ \\
& Type of adverse reaction & $45 \%$ \\
Information & First name and surname & $42 \%$ \\
on the & Signature & $39 \%$ \\
reporting & Telephone number & $92 \%$ \\
person & Address of residence & $83 \%$ \\
& Initials & $72 \%$ \\
& Correspondence address & $71 \%$ \\
& Profession & $63 \%$ \\
\hline
\end{tabular}

Abbreviations: NFZ, Polish National Health Fund; NIP, tax identification number; PESEL, Powszechny Elektroniczny System Ewidencji Ludności [English: personal identification number].

a university degree, $5 \%$ completed a vocational school, and $2 \%$ completed primary school.

The majority of the individuals who took part in the survey lived in the city $-62 \%$ of the respondents, while the remaining $38 \%$ lived in the countryside.

Nearly all the respondents, that is, $90 \%$, took the drugs under an urgent treatment. Only $10 \%$ took the drugs in relation to a chronic disease.

Adverse reactions were experienced by $8 \%$ of the respondents. Some respondents listed the products that had adverse reactions (although they have not been asked) - the substances that prevailed, in order, were acetylsalicylic acid that caused gastric symptoms, and valproic acid (VPA) weight gain. Table 1 presents sociodemographic characteristics of the patient population.

\section{The respondents answers on monitoring of adverse reactions}

The majority of the respondents believe that doctors (90\%) can report the ADRs and that patients, too, are entitled to do it $(75 \%)$. 
In terms of the authority that the adverse reactions should be reported to, the majority of the respondents indicated the Ministry of Health (95\%), URPLWMiPB (90\%), and the Main/Voivodeship Pharmaceutical Inspectorate $(75 \%)$.

The respondents claim that adverse reactions should be reported on a CIOMS form (32\%), the form placed on the website of the relevant pharmaceutical company (27\%), on a sheet of paper with all relevant information (26\%), or by means of a yellow card (8\%).

The majority of respondents (69\%) believe that ADRs might be reported in person or by email or post.

The largest number of the respondents (67\%) claim that serious adverse reactions are subject for reporting. A slightly smaller number of the respondents (62\%) believe that adverse reactions not covered by the package leaflet and those that are covered by the package leaflet (31\%) must be reported.

Asked about products not covered by monitoring, the majority of the respondents (58\%) stated that it applies to dietary supplements. The distribution of answers to particular questions on the means of reporting of ADRs is presented in Table 2. The data does not give a total of $100 \%$ because the respondents could choose multiple answers. There was a statistically significant association in terms of the knowledge of reporting tools for adverse reactions and the place of residence of the respondents. The respondents who lived in the city had greater knowledge compared to the respondents who lived in the countryside (Pearson's $\chi^{2}=47.70$, $P=0.0013$ ). The respondents who lived in the city were also more statistically likely to provide a correct answer to the question about the type of adverse reactions to be reported (Pearson's $\chi^{2}=50.66, P=0.012$ ).

\section{The respondents answers on data to be included in the report}

The question whose aim was to verify patient knowledge about the data to be included in the report was divided into three parts. The first part concerned information on the patient that must be included in the report. The first three positions, in order, were taken by data such as: first name and surname, Powszechny Elektroniczny System Ewidencji Ludności (PESEL; personal identification number) and telephone number ( $90 \%$ vs $72 \%$ vs $69 \%$, respectively).

The second part concerned the drug and the adverse reaction. The majority of the respondents believe that the report must include the trade name of the drug (93\%), a description of the adverse reaction ( $88 \%$ ), and the date of occurrence of the adverse reaction $(83 \%)$.
The third and final part concerned the person who reports the adverse reaction. Choices such as first name and surname $(92 \%)$ and signature (83\%) prevailed here.

The distribution of answers to particular questions about the data to be included in the report is presented in Table 3. The data does not give a total of $100 \%$ because the respondents could choose multiple answers.

Statistically significant associations were found between the place of residence of the respondents and the correct answer to the question about the data that must be included in the report on adverse reactions (Pearson's $\chi^{2}=11.7$, $P<0.0001)$.

\section{Discussion}

In Poland, the obligation to report adverse reactions of medicinal products initially applied to doctors and pharmacists. ${ }^{9}{ }^{10}$ Starting from 2013, patients, too, can report adverse reactions of drugs. ${ }^{7}$ With reference to the results of authors' original study, one should stress that the majority of the respondents were aware that adverse reactions might be reported by a doctor (90\%) and patient (75\%). However, a large percentage of the respondents were not aware of the fact that every health professional has such entitlements. According to a research study by Schetz et al conducted in Pomorskie Voivodeship, as many as $87 \%$ of analyzed doctors thought that the reports on ADRs should be delivered only by doctors, and only $9 \%$ of doctors thought that patients, too, should have such rights. ${ }^{11}$

Despite the upward trend in the number of reports on ASRs in Poland, the number is still not satisfactory compared to other countries. The data collected by WHO for 2013 indicates that $7.3 \%$ of reports were submitted in the UK, 6\% - in Germany, 3.1\% - in France, and around 2\% in Italy and Spain. In Poland, we had around 11,000 reports, 30 out of which were submitted by the patients themselves (in the other countries, nearly half of the reports are submitted by patients). ${ }^{12}$ In Denmark, patient reporting of ADRs commenced in 2004. In the period 2004-2006, 8.6\% reports were submitted by patients. ${ }^{13}$ In the Netherlands, since April 2003, patients can also report ADRs. In 2005, 13\% reports were submitted by patients, ${ }^{14}$ and in the period 2004-2007, a total of 2522 reports (5401 suspected ADRs) were received from patients and 10,635 reports (16,722 suspected ADRs) from heath care professionals. ${ }^{15}$ In Canada in 2008, 10.6\% reports were submitted solely by patients. ${ }^{16}$ In the USA, in 2008 , of the 226,647 reports, $46 \%$ were submitted by patients. The proportion of total reports submitted by patients has increased since the mid-1990s. ${ }^{17}$ 
A comforting fact is that according to the authors' original study, $90 \%$ of the patients knew that the suspected ADRs must be reported to URPLWMiPB. Unfortunately, a large percentage of the respondents also chose an incorrect answer pointing to different institutions, eg, the Ministry of Health (95\%) or the Main/Voivodeship Pharmaceutical Inspectorate (65\%). Not all doctors know where they should report adverse reactions; $89 \%$ of them pointed to the right place. ${ }^{11}$

According to the relevant laws of Poland, the suspected ADRs might be reported on the so-called yellow card, international CIOMS form, forms available from the accountable entities, or on a sheet of paper containing minimum required information. For the application to be valid, it must include information such as: identification data of the patient, description of adverse reaction (one or more), name of medicinal product/active ingredient that caused the adverse reaction, and identification data of the reporting person. ${ }^{8}$ In the authors' original study, the patients indicated that they would report the adverse reaction by means of a CIOMS form $(32 \%)$ or a form available from the pharmaceutical company or a sheet of paper with required information $(27 \%$ and $26 \%$, respectively). The number of those who pointed to the so-called yellow card was smaller $(8 \%)$. Nonetheless, every method indicated by the patients was a correct option.

Another reason to be satisfied is that all the patients who participated in the authors' original study knew how they can report an ADR. Although the respondents chose answers such as "only in person" ( $99 \%)$, "by email" (72\%), "by post" $(69 \%)$, or all of the above (69\%), all the methods indicated by the patients are allowed.

The patients were also asked about adverse reactions that should be reported. Most respondents stated that serious adverse reactions must be reported (67\%). The patients were right to declare that adverse reactions not covered by the package leaflet $(62 \%)$ and reactions covered by the leaflet (31\%) need to be reported.

It should be stressed that even the recognized and confirmed adverse reactions should be reported as it may help in the identification of the most dangerous drug(s) out of a therapeutic group. Some of the respondents mistakenly claimed that only those adverse reactions experienced by a given patient for the first time should be reported (19\%) or those reactions that are frequently experienced by a given patient (11\%). An alarming fact is that only $58 \%$ of doctors covered by a study of Schetz et al thought that all serious ADRs should be reported. ${ }^{12}$

Over a half of the patients (58\%) rightly said that adverse reactions of dietary supplements should not be reported to
URPLWMiPB, and 32\% would not report adverse reactions of medical devices. One should stress that the answers given by the respondents, such as: herbal medicines (45\%), homeopathic medicines (28\%), drugs applied in inpatient treatment (22\%), and imported drugs (17\%), are covered by the reported products because the reporting obligation applies to all adverse reactions associated with the use of any type of drugs.

The final question included in the survey referred to the information on the patient, drug, and adverse reaction and the reporting person that must be included in the report form. In terms of the information concerning the patient, most respondents pointed to first name and surname (90\%) and PESEL (72\%). The most important information, however, includes the initials, sex, and age and information about the weight of the patient (in case of patients with atypical weight and children). ${ }^{8}$ In the authors' original study, $61 \%$ of the respondents pointed to date of birth, $52 \%$ pointed to sex, and $19 \%$ pointed to weight. In terms of the information about the drug and adverse reaction, the majority of the respondents pointed to the trade name of the drug $(93 \%)$, description of adverse reaction ( $88 \%)$, and date of occurrence. In a study of the attitudes among doctors in Pomerania to the obligation of reporting of ADRs, $71 \%$ of the doctors pointed out that it is important to indicate the trade name of the drug with suspected adverse reaction. ${ }^{12}$ In reality, the report should contain the name of the drug and description of the adverse reaction. ${ }^{8}$ In the section that referred to the reporting person, the respondents listed the following data as required: first name and surname (92\%) and signature (83\%). In reality, first name, surname, and address of employment in case of medical personnel are enough. ${ }^{8}$

Statistically significant relations between the place of residence of the respondents and the correct answer to the question about the data that must be included in the report on adverse reactions (Pearson's $\chi^{2}=11.7, P<0.0001$ ), the knowledge on the means of reporting of ADR (Pearson's $\chi^{2}=47.70$, $P=0.0013)$, and the type of adverse reaction to be reported (Pearson's $\chi^{2}=50.66, P=0.012$ ) were found. The general knowledge on the reporting of ADRs was greater among city dwellers. Similar relations that referred to patient knowledge on ADRs were found by Kadhim who evaluated reporting of ADRs by patients in Iraq. ${ }^{18}$ The authors' original study was conducted in Mazowieckie Voivodeship; the majority of respondents resided in the city (62\%). In Warsaw, there was a campaign about the reporting of ADRs, which might explain the greater knowledge of the respondents.

A comforting fact is that $92 \%$ of the patients have never experienced any ADRs. Among those who have experienced 
adverse reactions, the reactions were associated with the use of aspirin and VPA.

Reporting of adverse reactions of medicinal products is a key element of drug policy in every state. It allows for accumulation of important information concerning the safe use of drugs. Unfortunately, $21 \%$ and $40 \%$ of doctors who participated in the study conducted by Schetz et al respectively considered reporting of ADRs to play a "very important" and "important" role in the improvement of safety of drug treatment. ${ }^{11}$ Research conducted in other countries - USA, ${ }^{19}$ Norway, ${ }^{20}$ Portugal, ${ }^{21}$ Hong Kong, ${ }^{22}$ the UK, ${ }^{23,24}$ Turkey, ${ }^{25}$ and Jordan ${ }^{26}$ also points to low awareness in respect of reporting of adverse reactions among pharmacists. In a study by Herdeiro et al, it was shown that hospital pharmacists report ADRs 20 times more frequently than community pharmacists, this was due to the fact that the hospital pharmacist was better educated and informed about pharmacovigilance practice. ${ }^{27}$ On the other hand, in a study by Abdel-Latif and Abdel-Wahab, pharmacists were the most knowledgeable group (70.27\%) about pharmacovigilance and ADRs reporting (other health care professional: physicians, nurses, and pharmacists' technicians). ${ }^{28}$ Therefore, there is a need for continuing education in the society, including among the people with a medical degree in terms of the role of and need for monitoring of adverse reactions of medicinal products.

Since November 2015, ADRs in Poland might be reported by means of a smartphone application known as Mobit Skaner. Perhaps, this solution will improve the number of reported adverse reactions - the app is extremely easy to use. After installation, the patient just needs to scan the barcode on the drug package and will instantly receive all basic information about the product and be able to report an adverse reaction via the app. The patient will need to complete some boxes in a form - there is no need to know what information is required and where the form must be sent. One can hope that thanks to new technology the whole procedure for reporting of adverse reactions will become easier, nonetheless, education is still a key element in this respect.

\section{Conclusion}

On the basis of the conducted survey, one can conclude that patient knowledge about reporting of adverse reactions is relatively low. Patients are unaware of the gravity of occurrence of adverse reactions and the high value of information about adverse reactions. Patients have contradictory information as to how they should proceed in the event of occurrence of adverse reactions. Hence, the knowledge must be broadened, otherwise, ignorance will spread. In order to improve the safety of the drugs there is a need to show the important role of adverse reactions reporting for public safety and make clear and easy procedures to report ADRs. The patients' education by health care providers and the workers of Department for Monitoring Adverse Reactions of Medicinal Products at the Office for Registration of Medicinal Products, Medical Devices and Biocidal Products on issues pertaining to ADRs reporting could help the involvement of patients in ADRs reporting process. The mass media campaigns seem to play a key role in reporting ADRs.

\section{Limitations}

There are a number of limitations on the study: it was conducted on a relatively small group of patients, it was conducted only in Mazowieckie Voivodeship, it is concerned only with the basic aspects associated with reporting of ADRs. However, the fact that this is the first and, so far, the only study on patient knowledge on reporting of adverse reactions, conducted in Poland is worth a mention. Hence, it should constitute a foundation for further detailed research.

\section{Disclosure}

The authors report no conflicts of interest in this work.

\section{References}

1. Ivy SP, Siu LL, Garrett-Mayer E, Rubinstein L. Approaches to phase 1 clinical trial design focused on safety, efficiency, and selected patient populations: a report from the clinical trial design task of national cancer institute investigational drug steering committee. Clin Cancer Res. 2010;16(6):1726-1736.

2. Vlahakes GJ. The value of phase IV clinical testing. $N$ Engl J Med. 2006;354(4):413-415.

3. Wiela-Hojeńska A, Jaźwińska-Tarnawska E. Międzynarodowe i krajowe systemy monitorowania niepożądanych działań leków - ich rozpoznawanie i zgłaszanie. Farm Pol. 2009;65:725-732. Polish.

4. The WHO Programme for International Drug Monitoring, Available from: http://www.who.int/medicines/areas/quality_safety/safety_efficacy/National_PV_Centres_Map/en/. Accessed May 26, 2016.

5. WHO Programme Members. Countries participating in the WHO Programme for International Drug Monitoring, with year of joining, Available from: http://www.who-umc.org/DynPage.aspx?id=1 $00653 \& \mathrm{mn} 1=7347 \& \mathrm{mn} 2=7252 \& \mathrm{mn} 3=7322 \& \mathrm{mn} 4=7442$. Accessed June 11, 2016.

6. Notice of the President of Office for Registration of Medicinal Products, Medical Devices and Biocidal Products of 3 November 2015. Zgłoś działanie niepożądane [Report a side effect]. Available from: http://www.urpl.gov.pl/pl/produkty-lecznicze/monitorowaniebezpiecze $\%$ C $5 \% 84$ stwa-lek $\%$ C3\%B3w/zg $\%$ C $5 \% 820 \%$ C $5 \% 9 B-$ dzia\%C $5 \% 82$ anie-niepo $\%$ C5\%BC $\%$ C $4 \% 85$ dane-0. Accessed October 13, 2016.

7. Directive of the European Parliament and of the Council no. 2010/84/ EU of 15 December 2010 amending - as regards pharmacovigilance Directive 2001/83/EC on the Community code relating to medicinal products for human use.

8. Drug safety monitoring, Available from: http://www.urpl.gov.pl/ $\mathrm{pl} /$ produkty-lecznicze/monitorowanie-bezpiecze $\%$ C $5 \% 84$ stwalek\%C3\%B3w. Accessed June 11, 2016.

9. Acts of 5 December 1996 on the professions of a physician and dentist, as amended (Journal of Laws of 1997 no. 28, item 152). 
10. Regulation of the Minister of Health of 17 February 2003 on monitoring of the safety of medicinal products (Journal of Laws no. 47, item 405).

11. Schetz D, Sein Anand J. Postawy pomorskich lekarzy wobec obowiązku raportowania niepożądanych działań produktów leczniczych. Przegląd Lekarski. 2015;72(9):475-478. Polish.

12. Jakubik L. Polscy pacjenci rzadko zgłaszają niepożądane działania leków. To może się zmienić, Available from: http://www.rynekaptek pl/prawo/polscy-pacjenci-rzadko-zglaszaja-niepozadane-dzialanialekow-to-moze-sie-zmienic,5692.html. Accessed May 26, 2016.

13. Aagaard L, Hougaard LN, Holme EH. Consumer reporting of adverse drug reactions: a retrospective analysis of the Danish adverse drug reaction database from 2004 to 2006. Drug Saf. 2009;32(11):1067-1074.

14. Netherlands Pharmacovigilance Centre (Lareb). Annual Report from Netherlands Pharmacovigilance Centre. Hertogenbosch: Lareb 2005. Available from: www.lareb.nl. Accessed May 16, 2016.

15. de Langen J, van Hunsel F, Passier A, de Jong-van den Berg L, van Grootheest $\mathrm{K}$. Adverse drug reaction reporting by patients in the Netherlands: three years of experience. Drug Saf. 2008;31(6):515-524.

16. Health Canada. Adverse Reaction and Medical Device Problem Reporting, Available from: http:/www.hc-sc.gc.ca/dhp-mps/medeff/ report-declaration/index-eng.php. Accessed September 15, 2016.

17. Food and Drug Administration (FDA). Annual Adverse Drug Experience Report: 1996. Silver Spring, MD: FDA; 1997.

18. Kadhim AK. Self-reporting of adverse drug reactions in Iraqi hospitals: patient's perspectives. Pharmacol Pharm. 2015;6:566-572.

19. Generali JA, Danish MA, Rosenbaum SE. Knowledge of and attitudes about adverse drug reaction reporting among Rhode Island pharmacists. Ann Pharmacother. 1995;29(4):365-369.
20. Granas AG, Buajordet M, Stenberg-Nilsen H, Harg P, Horn AM. Pharmacists' attitudes towards the reporting of suspected adverse drug reactions in Norway. Pharmacoepidemiol Drug Saf. 2007;16(4):429-434.

21. Herdeiro MT, Figueiras A, Polonia J, Gestal-Otero JJ. Influence of pharmacists' attitudes on adverse drug reaction reporting: a case-control study in Portugal. Drug Saf. 2006;29(4):331-340.

22. Lee A, Thomas SHL. Adverse drug reactions. In: Walker R, Whittele C, editors. Clinical Pharmacy and Therapeutics. 4th ed. People's Republic of China: Churchill Livingstone, 2007.

23. Green CF, Mottram DR, Rowe PH, Pirmohamed M. Attitudes and knowledge of hospital pharmacists to adverse drug reaction reporting. Br J Clin Pharmacol. 2001;51(1):81-86.

24. Sweis DW, Wong IC. A survey on factors that could affect adverse drug reaction reporting according to hospital pharmacists in Great Britain. Drug Saf. 2000;23(2):165-172.

25. Toklu HZ, Uysal MK. The knowledge and attitude of the Turkish community pharmacists toward pharmacovigilance in the Kadikoy district of Istanbul. Pharm World Sci. 2008;30(5):556-562.

26. Suyagh M, Farah D, Farha RA. Pharmacist's knowledge, practice and attitudes toward pharmacovigilance and adverse drug reactions reporting process. Saudi Pharm J. 2015;23(2):147-153.

27. Herdeiro MT, Figueiras A, Polonia J, Gestal-Otero JJ. Influence of pharmacists' attitudes on adverse drug reaction reporting: a case-control study in Portugal. Drug Saf. 2006;29(4):331-340.

28. Abdel-Latif MM, Abdel-Wahab BA. Knowledge and awareness of adverse drug reactions and pharmacovigilance practices among healthcare professionals in Al-Madinah Al-Munawwarah, Kingdom of Saudi Arabia. Saudi Pharm J. 2015;23:154-161.
Patient Preference and Adherence

\section{Publish your work in this journal}

Patient Preference and Adherence is an international, peer-reviewed, open access journal that focuses on the growing importance of patient preference and adherence throughout the therapeutic continuum. Patient satisfaction, acceptability, quality of life, compliance, persistence and their role in developing new therapeutic modalities and compounds to optimize

\section{Dovepress}

clinical outcomes for existing disease states are major areas of interest for the journal. This journal has been accepted for indexing on PubMed Central. The manuscript management system is completely online and includes a very quick and fair peer-review system, which is all easy to use. Visit http://www. dovepress.com/testimonials.php to read real quotes from published authors. 